\title{
Meibomian Gland Disease. Classification and Grading of Lid Changes
}

\author{
A. J. BRON, L. BENJAMIN, G. R. SNIBSON \\ Oxford
}

\begin{abstract}
Summary
In recent years attention has been paid to meibomian gland dysfunction (MGD) as a distinct clinical entity responsible for chronic symptoms and signs and occurring independently or in association with atopy, cicatrising mucosal disorders and rosacea. Attempts to correlate MGD with microbiological and lipid biochemical changes are confounded by the absence of a clear descriptive language for the disorder and its associated changes. Such a language is crucial for the conduct of cross-sectional and natural history studies and therapeutic clinical trials. We present a comprehensive classification and grading scheme of meibomian gland disease, supporting our observations with illustrations.
\end{abstract}

Meibomian gland disease (MGD) is common and sometimes responsible for severe and chronic symptoms and secondary conjunctival and corneal changes. The purpose of this paper is to review its components, with particular attention to definition and illustration.

\section{Normal Meibomian Gland Anatomy and Physiology}

The most anterior zone of the tear film is the lipid layer which derives from oil secreted onto the lid margin by the meibomian glands, and layered onto the surface of the preocular tear film with each blink. The functions of meibomian oil are listed in Table I.

The normal lid margin, measured from its posterior border to the posterior lash line is approximately $2.5 \mathrm{~mm}$ wide in the adult and presents a smooth flat surface whose posterior margin is sharply rounded at about a right angle, to conform to the surface of the globe. The posterior quarter consists of the marginal mucous membrane of the tarsal conjunctiva, while the anterior three quarters is skin. The anterior margin is less sharply rounded and its anterior half bears multiple rows of lashes. The meibomian gland orifices emerge just anterior to the mucocutaneous junction, which runs as a smoothly curving line, parallel to the posterior margin, from one end of the lid to the other (Fig. 1a). This cutaneous location is essential for the delivery of lipid onto the anterior face of the tear film. The ductal lining is composed of keratinised squamous epithelium. Jester et al. have sug-

Table I. Functions of meibomian lipid

1 Reduction of evaporation from the Meibomian preocular tear film

2 Enhancing tear film stability by lowering surface tension

3 Prevention of spill-over of tears from the lid margin

4 Prevention of contamination of the tear film by sebum

5 Sealing the apposed lid margins during sleep 
gested, on the basis of immuno-histochemical studies that keratinisation is partial, i.e. less than that of the neighbouring skin. ${ }^{1}$

There are about $30-40$ glands in the upper tarsus, and fewer, (20-40) in the lower. The fine orifices of the main ducts are flush with the surface and visible on biomicroscopy (Fig. 1b). In youth, each orifice exhibits a number of concentric circular zones. These are:

(1) a central punctum surrounded by an opaque cuff,

(2) a dark or translucent ring,

(3) a further opaque cuff. (Fig. 2).

The inner cuff is assumed to be the keratinised lining of the duct and the translucent zone the surrounding dermis. The outer, creamcoloured cuff is thought to be subepithelial, since it is absent from pigmented skin, where the epithelial pigmentation may obscure the outer cuff completely (Fig. 1c). The cuff may therefore be formed by a dermal or subdermal structure such as the muscle of Riolan or the distal tip of the Meibomian acinus. This requires histological demonstration. The meibomian glands were first clearly described by Heinrich Meibom. ${ }^{1 b}$

In youth and in young adults the intermarginal surface is relatively avascular. The papillary vasculature of the mucosa is visible in young lids, and with age a vascular architecture identifies itself increasingly on the cutaneous margin. Most characteristic of these is the vascular network which reaches the edge of the outer cuff of each meibomian orifice, and the venous network which has a segmental distribution between the orifices, and whose tributaries arise from the mucosa at the muco-cutaneous junction. They pass forwards in the dermis of the cutaneous margin, receiving branches from the pretarsal zone at the level of the grey line.

The macroscopic architecture of the meibomian acini is visible through the tarsal conjunctiva. The acinar lobules on either side of the central main duct are distinctly visible as yellow, grape-like clusters (Fig. 1d). With age, the visibility of the glands diminishes and they ultimately cannot be seen. This is assumed to be due to increasing opacity of the submucosal connective tissue and the tarsal plate itself.
The meibomian glands are tubulo-acinar and their mode of secretion is holocrine, that is, the contents of the secretory cell are lost in the process of secretion. The stimulus to secretion is not fully known. It is assumed that the secretion of meibomian oil is modulated by the levels of plasma sex hormones, since the meibomian glands are modified sebaceous glands and the role of the sex hormones in modulating sebaceous secretion is well known. Thus androgens such as testosterone increase, and oestrogens or anti-androgens (e.g. cyproterone acetate) reduce secretion. ${ }^{2-5}$ This information is not available for the meibomian glands. However, there is an association between meibomian gland disorder and seborrhoeic eczema on the one hand and the latter condition and androgens on the other which suggests that androgen levels may at least influence meibomian gland function. ${ }^{6}$

The meibomian glands have a rich innervation but this has not been fully investigated. Hartschuh et al. have demonstrated VIP-ergic innervation of human meibomian glands. ${ }^{7}$ Adrenergic and cholinergic innervation does not appear to have been studied, but it is of interest that an increase in secretion occurs after experimental section of the cervical sympathetic in laboratory animals. ${ }^{8}$ Also, a relationship between meibomian gland obstruction and epinephrine use has been documented thoroughly in the experimental model. ${ }^{9-11}$ It is however not known whether this is a toxic effect of the drug or an expression of adrenergic action. The features of epinephrine-induced MGD are: plugging of and an increase in the level of epithelial keratinisation of ducts; cystic dilatation of ducts and acini, and secondary compression or atrophy of acinar cells.

Meibomian oil is liquid at lid temperature. Its melting point range is- $19.5-32.9^{\circ} \mathrm{C} .{ }^{12}$ The mechanical action of the lids is regarded as important in the delivery of secreted lid oil onto the tear film. ${ }^{13 a, b}$ 'Jetting' of lid oil at the orifices just following a blink, has been reported, ${ }^{14,15}$ which would support such a view but would also be in keeping with secretion by other mechanisms. Tiffany discusses the forces which are brought to bear by lid closure. $^{16}$

A full account of meibomian lipid com- 


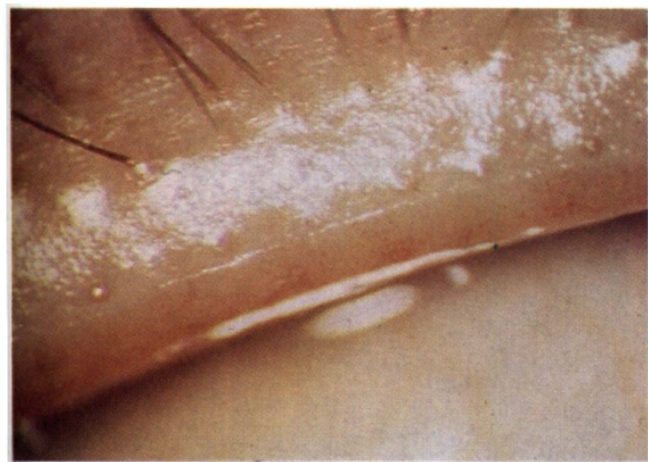

Fig. 1a. Normal lid margin: Male: 12 years cutaneous part seen in specular reflection. Mucocutaneous junction arrowed.

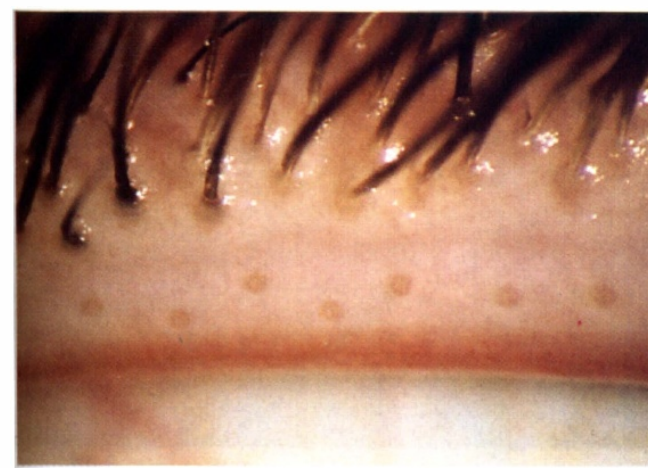

Fig. 1b. Normal lid margin. Male: Age 25 years. Normal Meibomian orifices, in this case disposed in an irregular manner anteroposteriorly. Grey line arrowed.

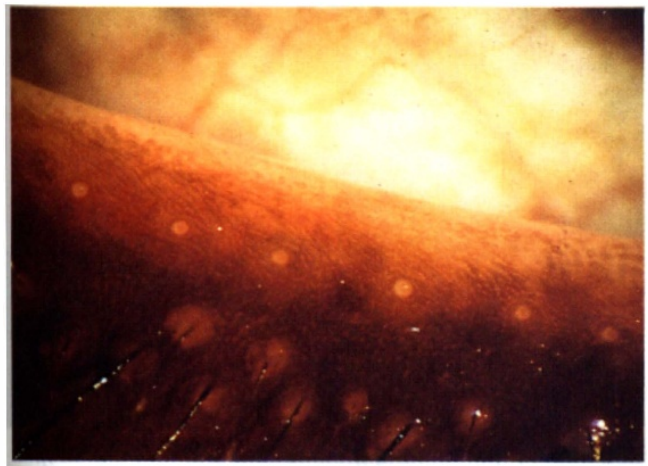

Fig. 1c. Normal lid margin. Pigmented: West Indian adult female. Only the punctum and inner cuffs of the Meibomian orifices are seen. The dermal ring and outer cuff are obscured by epithelial pigment.

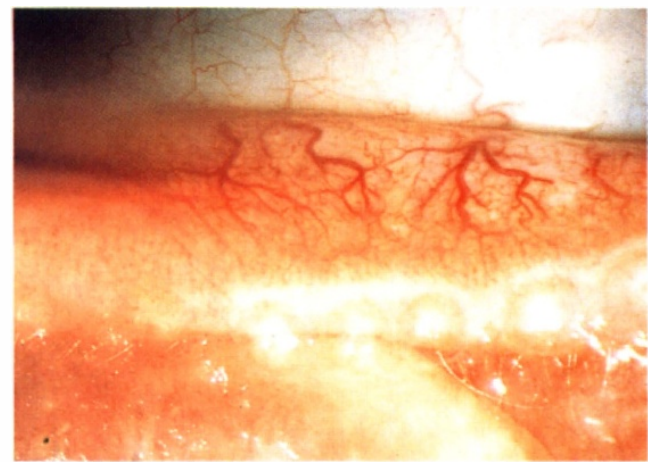

Fig. 1d. Normal tarsal plate: Male: Age 24 years. Acini seen through conjunctiva.

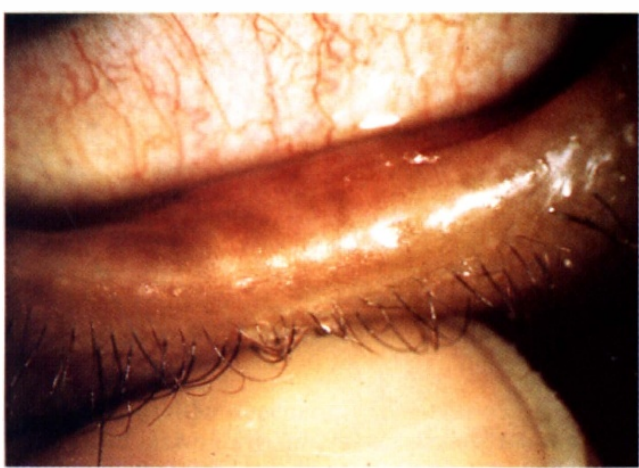

Fig. 1e. Chronic Meibomitis. Adult male. West Indian. Lower lid everted to show rounding of posterior lid margin.

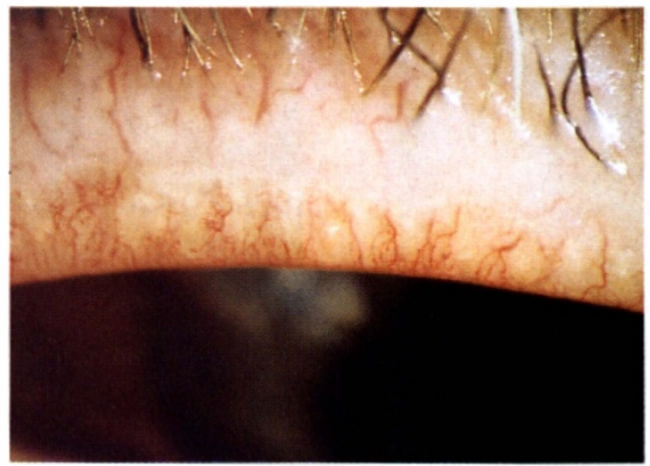

Fig. 1f. Meibomitis: Increased vascularity of the lid margin. 


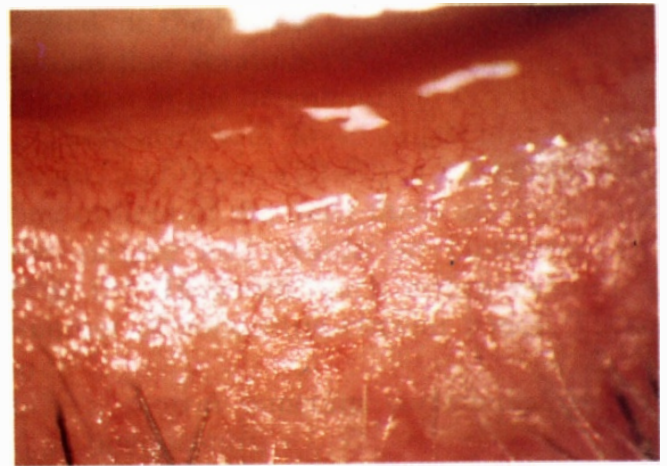

Fig. 1g. Meibomitis: 'Hyperkeratinisation' of the cutaneous part of the lid margin.

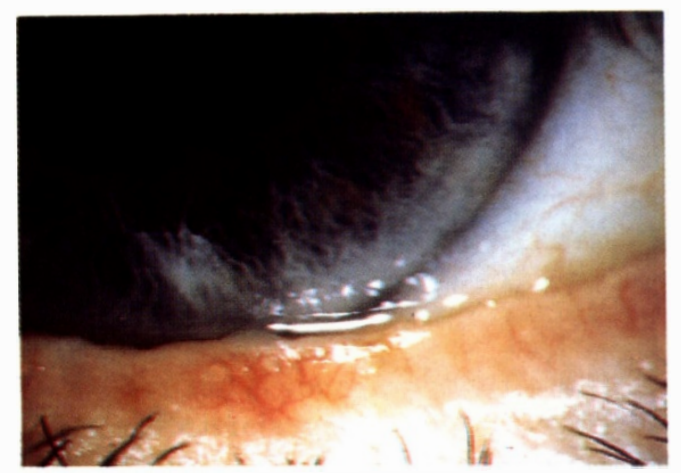

Fig. 1h. Meibomitis: Irregularity of the posterior lid margin.

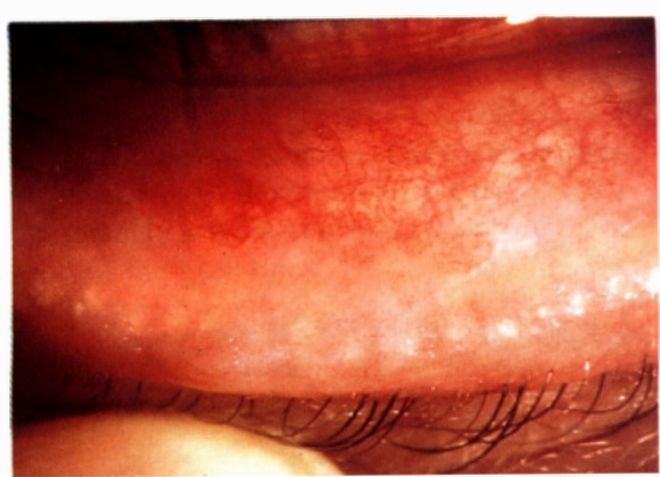

Fig. 1i. Severe Meibomitis in a patient with atopic keratoconjunctivitis Retroplacement of the mucocutaneous junction: The squamous metaplasia is well behind the irregular row of Meibomian orifices (arrow heads).

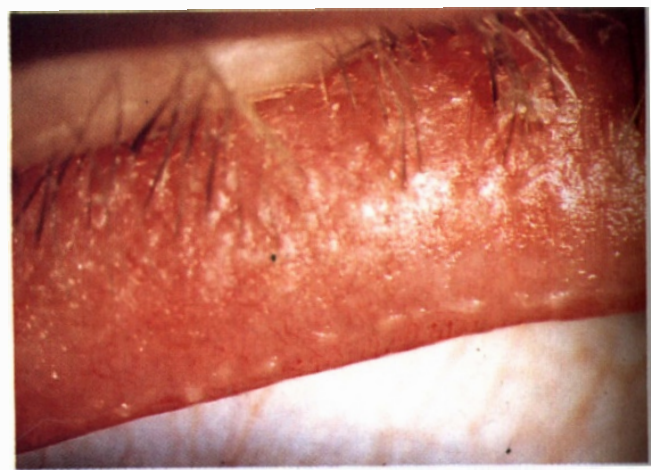

Fig. 1j. Ridging at the mucocutaneous junction running between an irregular row of Meibomian orifices.

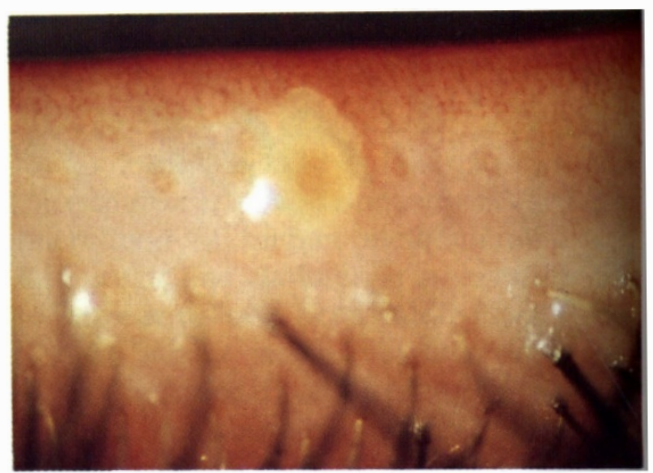

Fig. 1k. Capping of a Meibomian orifice. The neighbouring orifices are relatively normal.

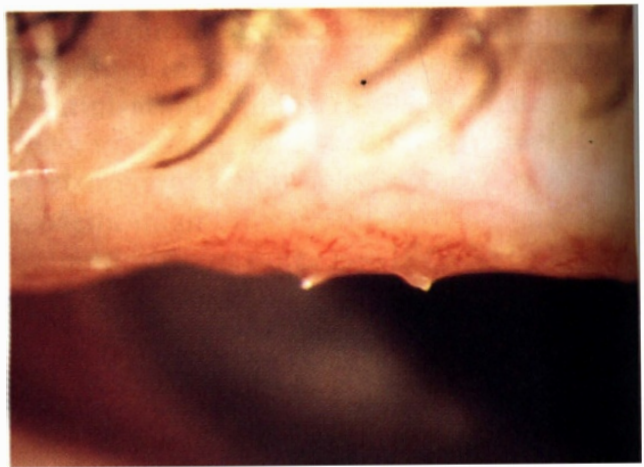

Fig. 11. Meibomitis: Pouting of 2 adjacent orifices (viewed in profile). 


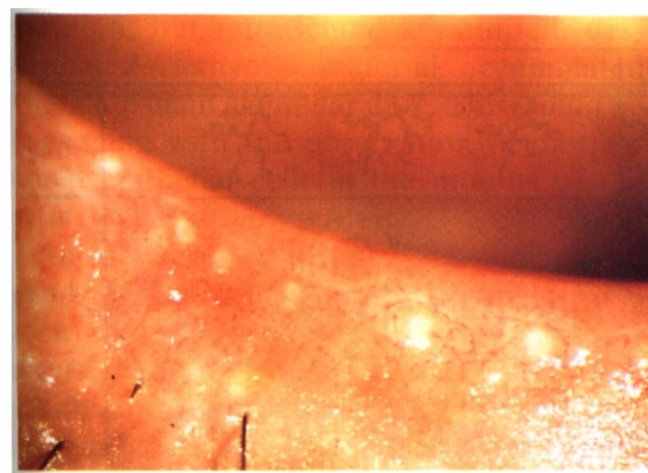

Fig. 1m. Opaque Meibomian orifices. Those on the left side of the picture are retroplaced.

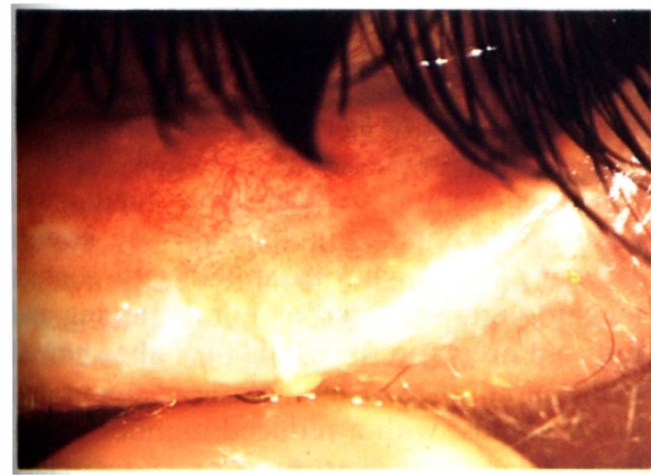

Fig. 1n. Severe MGD: The central orifices (arrowed) are opaque, and retroplaced. Adult patient with longstanding atopic kerato conjunctivitis.

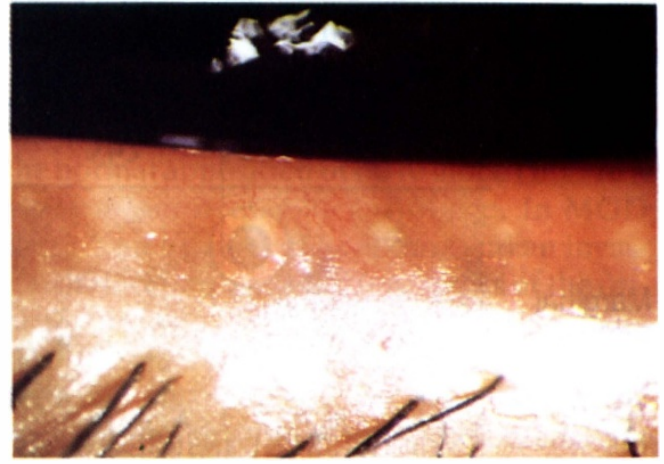

Fig. 1o. MGD: Opaque obliterated Meibomian orifices.

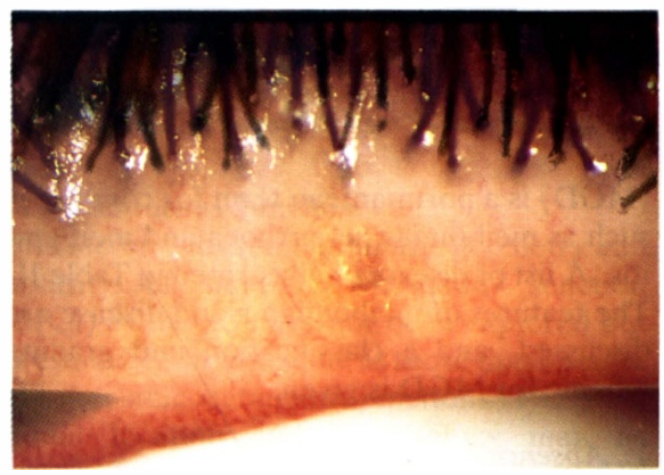

Fig. 1p. Globular degenerative changes seen at the lid margin and resembling spheroidal degeneration.

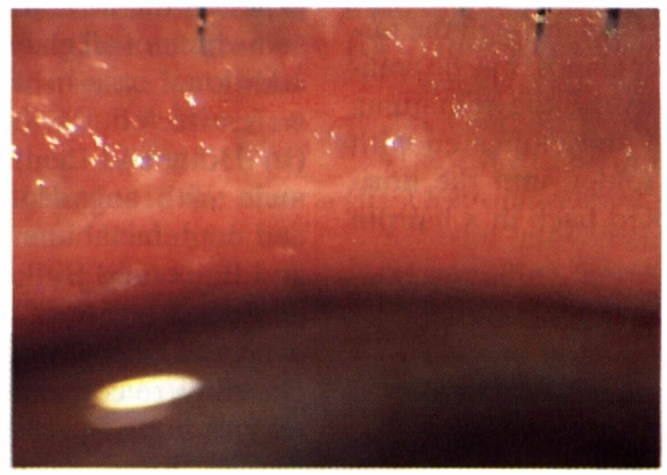

Fig. 1q. Atopic keratoconjunctivitis: Periductular fibrosis.

position is given by Tiffany; ${ }^{16}$ There are earlier reviews by Tiffany ${ }^{17}$ and Nicolaides. ${ }^{18}$ Anatomical accounts are given by Virchow , ${ }^{19}$ Duke Elder, ${ }^{20}$ Wolff $^{21}$ and Murube. ${ }^{22}$

\section{Meibomian Gland Disease}

Meibomian gland diseases are common, and some may be associated with systemic disease. Meibomian gland dysfunction 


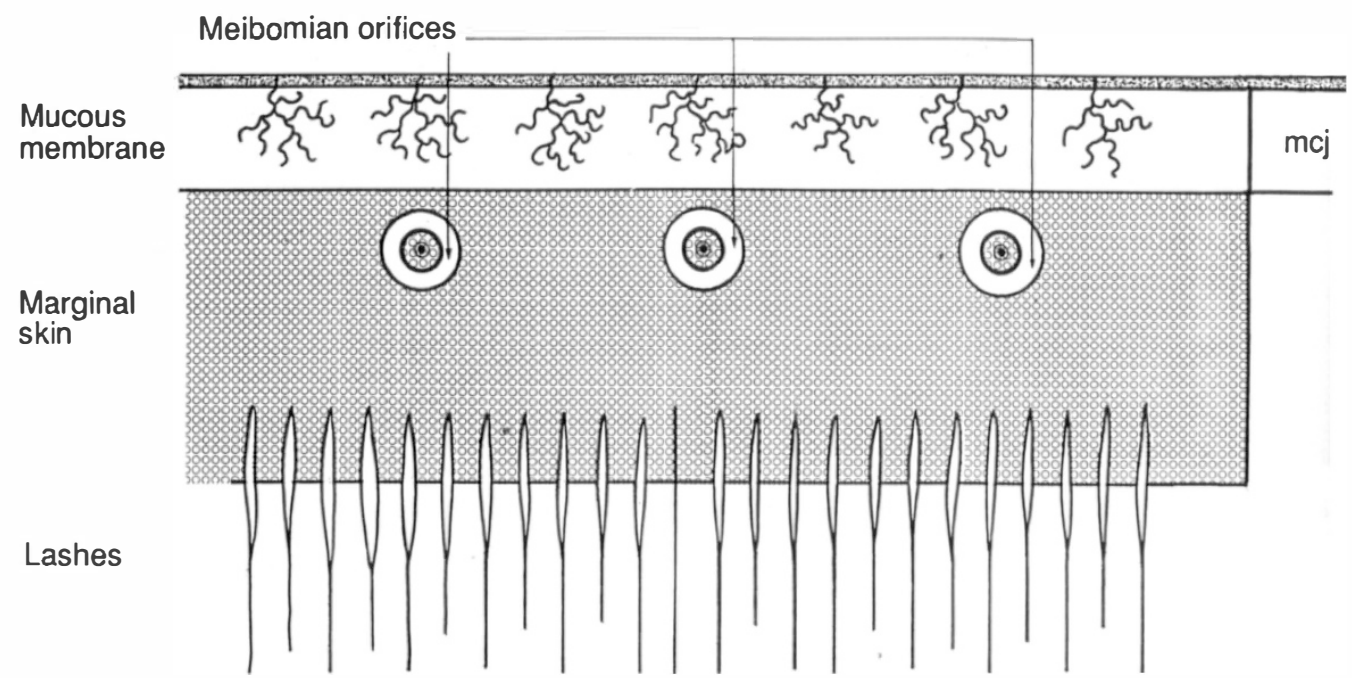

Fig. 2. Diagram of the Meibomian orifices and mucocutaneous junction of the lid margin.

(MGD) is a portmanteau term for conditions such as meibomian seborrhoea and meibomitis. A list of diseases is illustrated in Table II. The features of meibomian gland disease are discussed, and a classification and grading scheme for MGD is given.

\section{Absence and Deficiency}

Absence or deficiency of the meibomian glands may be congenital and are characterised by an absence or reduced number of orifices at the lid margin. Rudimentary glands may be seen as yellow streaks through the tarsal conjunctival surface or glands may be completely absent. Alternatively, the remaining glands may be enlarged and elongated with their proximal portion folded into the horizontal meridian or hooked back in a hairpin manner.

Table II Meibomian gland diseases

\begin{tabular}{l}
\hline Absence or deficiency \\
OPrimary: Congenital \\
Anhydrotic ectodermal dysplasia \\
Ectrodactyly, ectodermal dysplasia, cleft \\
lip and palate \\
Icthyosis \\
OSecondary:to lid disease \\
2 Replacement \\
OPrimary: Dystichiasis \\
OSecondary:dystichiasis due to metaplasia \\
3 Meibomian Seborrhoea \\
4 Meibomitis \\
5 Meibomian neoplasia
\end{tabular}

(a) A congenital deficiency of meibomian glands was reported in an otherwise normal 16-year-old girl who presented with contact lens intolerance, interpalpebral staining and reduced break up time (BUT). ${ }^{23}$ She showed bilateral absence or hypoplasia of upper and lower glands, with a reduced number of orifices. Glands were stunted or rudimentary and some gland rudiments were not associated with a meibomian orifice. Other glands of more normal length were obliquely disposed in the lid; oil could be expressed from some but not all glands. We have since seen an additional case in which only the lower lids were affected.

(b) Holly and Lemp described a 21-year-old male with anhydrotic ectodermal dysplasia and no detectable meibomian gland orifices ${ }^{24}$ and Baum and Bull, and Mondino et al. each described a case of ectrodactyly, ectodermal dysplasia, cleft-lip and palate, in which the glands were congenitally absent. ${ }^{24.25 .26}$

(c) An unusual meibomian gland abnormality was described in a boy with icthyosis in whom normal meibomian orifices were present but in whom pressure over the tarsal plates expressed a thick coil of inspissated material of toothpaste consistency. ${ }^{27}$ The meibomian 'glands' appeared as cigar-shaped yellow streaks, brigher than normal and lacking the usual racemose morphology. It is likely that the expressed material was not a lipid 
secretion, but represented keratinised, desquamated, icthyotic material accumulated within the main glandular duct. This would be in keeping with the observation of desquamated epithelial cells in the mouths of the ducts demonstrated in MGD. ${ }^{28-30}$

An acquired deficiency of meibomian glands is frequently encountered in association with destructive lid disease. It thus occurs with staphylococcal and atopic blepharitis and in forms of cicatrising conjunctivitis such as trachoma, mucous membrane pemphigoid and erythema multiforme. Clinical features include absent or puckered and occluded duct orifices and sufficient cicatricial disorganisation of the affected portions of the lid to make it impossible to assess the extent of gland substance present.

\section{Replacement of Meibomian Glands}

In dystichiasis, an extra row of lashes takes the place of the meibomian glands. The condition may be partial or complete and may be inherited (e.g. as a dominant) or acquired focally as a metaplastic reaction to mucocutaneous disease of the lids.

\section{Meibomian Gland Dysfunction}

Meibomian gland dysfunction will be used here to imply an affection of the meibomian glands, without necessarily implying that inflammation is present. It is often associated with changes in the lid beyond the confines of the glands themselves. This section will deal in particular with the individual features of MGD. These are described in relation to mucocutaneous changes, changes in the meibomian orifices, ducts, and acini and the secretory' performance of the gland.

Features are described topographically to include changes at the margin, mucocutaneous junction, orifices, ducts, acini and on the tarsal plate. Grading varies according to the features. Greater detail is given in Table III and is illustrated in Figures 1 and 3.

\section{Lid Margin}

Thickening of the lid is a common feature of meibomian gland disease, but is difficult to measure because of the rounded contour of the anterior margin. It is best measured from the posterior margin to the posterior lash line, which are relatively constant features of the lid.

Rounding of the posterior lid margin is often associated with thickening and interferes with the normal apposition of lid to globe (Fig. 1e). Vascularisation increases with age. In MGD there is an exaggeration of this, and an invasion of the outer and then inner cuffs of the orifice. (Fig. 1f).

Hyperkeratinisation is an eczematised appearance of the cutaneous margin, frequently encountered in atopes with facial eczema but also in non-atopic subjects. (Fig. 1g).

Irregularity of the lid margin arises from absorption of tissue, often in the region of obliterated meibomian orifices but will occur with more gross distortions of lid architecture in cicatricial and ulcerative lid disease. (Fig. 1h).

\section{Mucocutaneous Junction}

The factors which maintain the geometry and polarity of the mucocutaneous junction (MCJ) of the lid have not been explored but presumably are the same as those that operate at other mucocutaneous junctions. The junctional location and morphology may be altered in MGD. The MCJ is best identified by its specular reflection. Although the position of the anterior edge of the tear meniscus may correspond with it in health, in disease it may not be an accurate guide.

(i) Anteroplacement: The junction becomes irregular in MGD. The mucosa may spread forwards, so that the orifices appear to lie in mucosal tissue.

(ii) Retroplacement: Here, there is a posterior movement of the MCJ, with a spreading, keratinising squamous metaplasia of the posterior lid margin, which extends onto the tarsal plate. The meibomian orifices may or may not move with the MCJ, which will determine whether the tear oil is delivered onto the surface of the tear film or not. Often, with severe disease, this question is redundant because the affected glands are non-functional. Retroplacement is more common than anteroplacement. (Fig. 1i).

(iii) Mucosal absorption: This may occur without retroplacement of the MCJ so 
Table IIIa. MEIBOMIAN ASSESSMENT PROFORMA

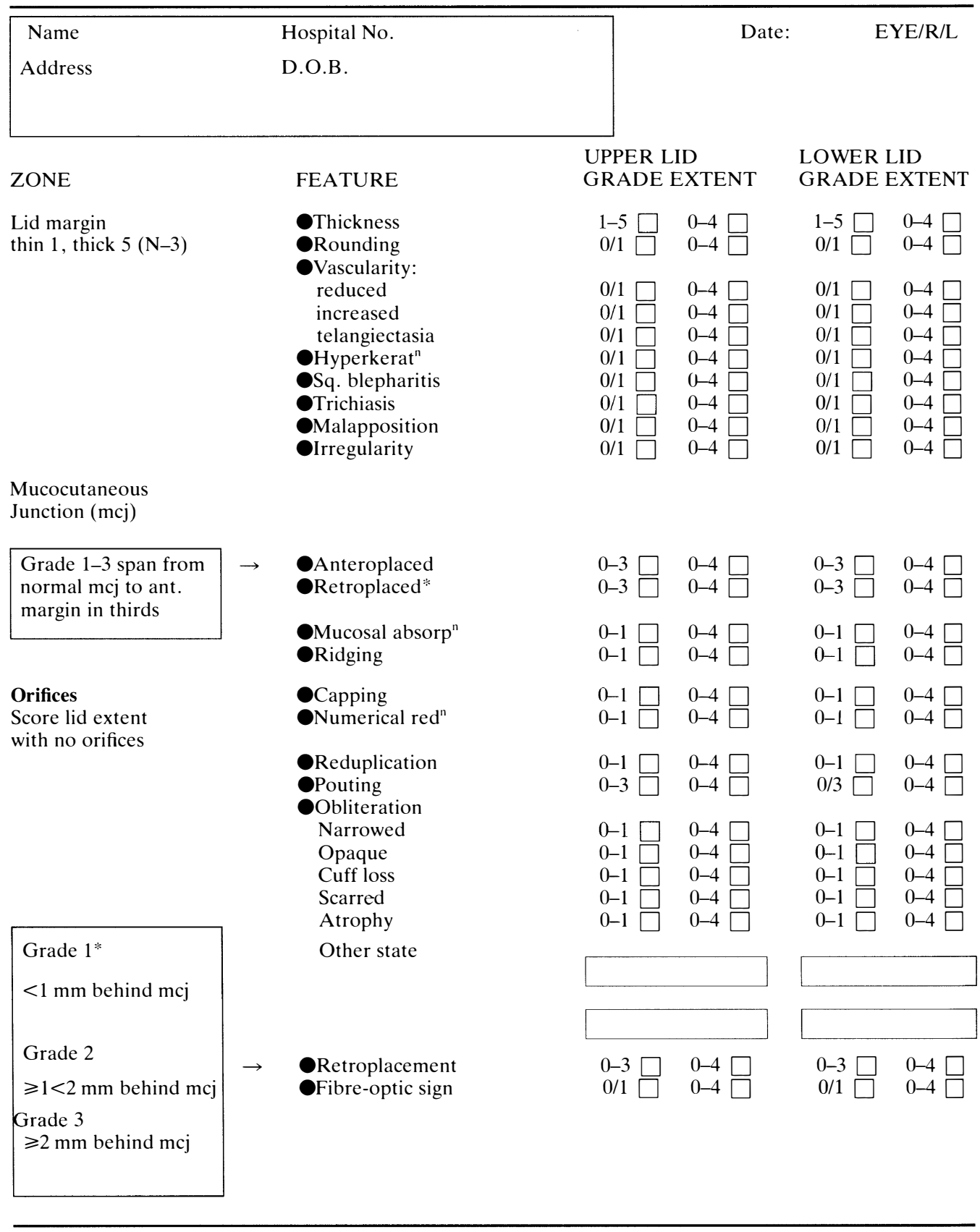

that the MCJ and orifices are still at the same distance from the lash line, but come to lie at a new posterior lid margin. (iv) Ridging: There is a ridge-like elevation of the MCJ or of tissue running between the orifices. It may be an effect of mucosal absorption when a new posterior margin is formed. (Fig. 1j). 
Table IIIb

Initials:

ZONE
FEATURES
Date:

UPPER LID

GRADE

EXTENT
EYE:R/L

LOWER LID

GRADE

EXTENT

Main ducts

$$
\begin{aligned}
& 1<1 \mathrm{~mm} \text { exposed } \\
& 2=\geqslant 1<2 \\
& 3=\geqslant 2 \mathrm{~mm}
\end{aligned} \quad \rightarrow \quad \begin{aligned}
& \text { OExposure } \\
& \text { OCystoid dil }
\end{aligned}
$$

Acini

$1=$ cluster visible
$2=$ yellow stripe
$3=$ not visible
$1=$ deep
$2=$ subepithelial
$3=$ extruding

Secretions expressed

$0=$ normal $1=$ delay

3 = blockade

$0=$ clear $1=$ cloudy

$2=$ granular

$3=$ opaque solid

$$
\begin{aligned}
\rightarrow \text { OVisibility } \\
\\
\text { ORudimentry } \\
\text { OEnlarged } \\
\rightarrow \text { OConcretions } \\
\text { OChalazia }
\end{aligned}
$$

Onc. quantity

\begin{tabular}{|c|c|c|c|}
\hline $1-3 \square$ & $0-4 \square$ & $1-3 \square$ & $0-4$ \\
\hline $0 / 1$ & $0-4$ & $0 / 1$ & $0-4$ \\
\hline $0 / 1$ & $0-4$ & $0 / 1$ & $0-4$. \\
\hline$0 - 3 \longdiv { \square }$ & $0-4 \bar{\square}$ & $0-3$ & $0-4$ \\
\hline $0 / 1 \square$ & $0-4 \square$ & $0 / 1$ & $0-4$ \\
\hline $0 / 1 \square$ & $0-4 \square$ & $0 / 1 \square$ & $0-4$ \\
\hline $0-3$ & $0-4$ & $0-3$ & $0-4$ \\
\hline $0-3$ & $0-4$ & 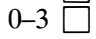 & $0-4$ \\
\hline $0 / 1 \square$ & $0-4 \square$ & $0 / 1 \square$ & $0-4$ \\
\hline
\end{tabular}

Dec. quantity

Ouality

OFoam
$0-3$

$0-3$

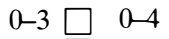

$0-3 \square \quad 0-4$

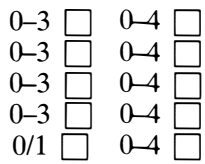

$0 / 1 \square \quad 0-4 \square$

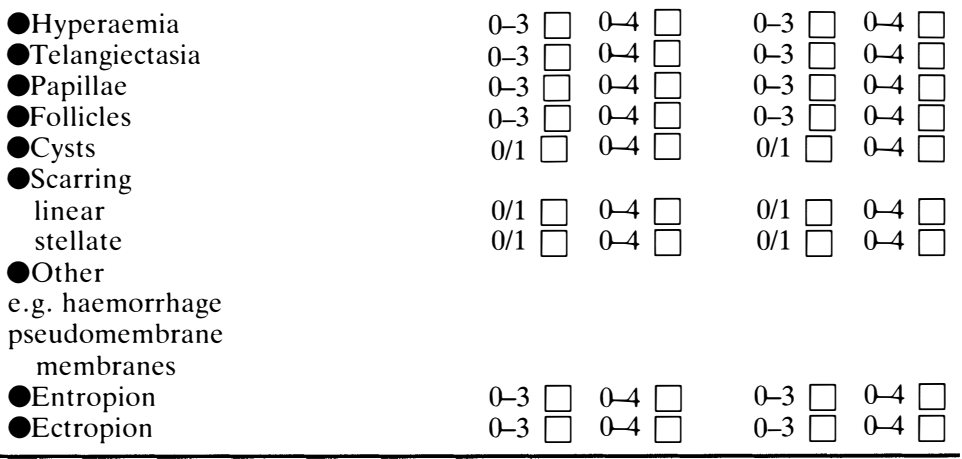

\section{Orifices}

(i) Number: the orifices may be reduplicated, or reduced in number, either congenitally, sometimes as part of a syndrome, or as an acquired feature of MGD. (ii) Capping: This was described by Theodore ('meibomiana'), and also by Keith. Scattered orifices may be capped by a dome of oil whose surface is tough but may be pierced by a needle-tip to release plentiful oil. Keith noted that the 


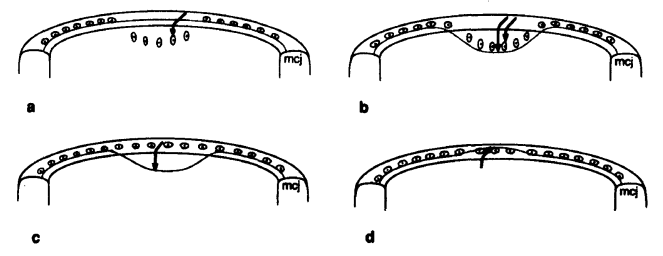

Fig. 3. Diagram illustrating malposition of the Meibomian orifices and mucocutaneous junction. a) Retroplacement of orifices b) Retroplacement of orifices and mucocutaneous junction c) Retroplacement of mucocutaneous junction d) Anteroplacement of mucocutaneous junction.

underlying orifice was ulcerated, and suggested that the cap was epithelialised. ${ }^{31}$ We hypothesise that the surface lipids are oxidised and hence more saturated, so that they solidify at lid temperature or below to produce a surface skin. (Fig. 1k).

Capping usually affects only occasional orifices and may be found in otherwise normal lids.

(iii) Pouting: An early sign of meibomian gland disease is elevation or pouting of the orifice, which is no longer flush with the surface. The meibomian orifice may be dilated, and expression may demonstrate the terminal ductule to be plugged with inspissated secretion or other material. However, such pouting orifices may also be blocked. At times, incipient exposure of the ductule (vide infra) may give this appearance. (Fig. 11).

(iv) Retroplacement: This term is employed to describe the result of a cicatricial process involving the posterior lid margin and may be associated with more extensive cicatricial changes within the tarsal mucous membrane near the marginal mucosa. The orifices may become ovally elongated in the plane of the ducts and posterior movement may be accompanied by duct exposure. (Fig. $1 \mathrm{~m}, \mathrm{n}$ ).

(v) The fibre optic sign: A change in the light-conducting properties of the meibomian ducts may occur, so that illumination of the tarsal plate from the conjunctival surface with a slit-lamp source, or through the skin with a fibreoptic source, causes the affected orifice to 'light up'. ${ }^{32}$ This is most likely to be seen in the presence of pouting, or cystoid dilatation of the duct or gland. (Fig. 4a).

(vi) Obliteration: Narrowing: The punctum of the orifice may not be visible. This appearance may be associated with reduced expressibility of lipid. It is not certain if this sign can occur in the absence of other features of obliteration.

Loss of definition of the cuffs of the orifices is a feature which is seen with age and in early MGD.

Vascular invasion may accompany the process of loss of definition. (Fig. 4b).

Opaque orifices: Here, the degree of opacity of the inner cuff becomes accentuated. Opaque orifices are far more visible at the lid margin than normal. (Fig. 10).

Scarring of the region of the orifices may occur, with tissue loss and depression of the surface. It is often accompanied by a range of degenerate changes at the lid margin. (Fig. 1p).

It seems likely that the whole of the above process results from subepithelial cicatricial change which drags the posterior lid margin towards a cicatricial epicentre. It is not clear whether there is a true 'absorption' of lid substance in addition to scarring, though both might be envisaged to occur.

Atrophic obliteration consists of a disappearance of the orifice landmarks so that the surface epithelium may be relatively smooth and the past location of the orifice is marked by the tip of the distal acinus seen through the marginal epithelium (Fig. 4c).

An interesting feature observed in one atopic patient was a peri-ductular fibrosis (Fig. 1q).

\section{Main Ducts}

(i) Exposure: Exposure of the terminal duct of the gland in varying degrees is a common feature of MGD, suggesting the presence of an irreversible cicatricial process in the adjacent submucosa. The duct, as it forms the orifice at the lid mar- 


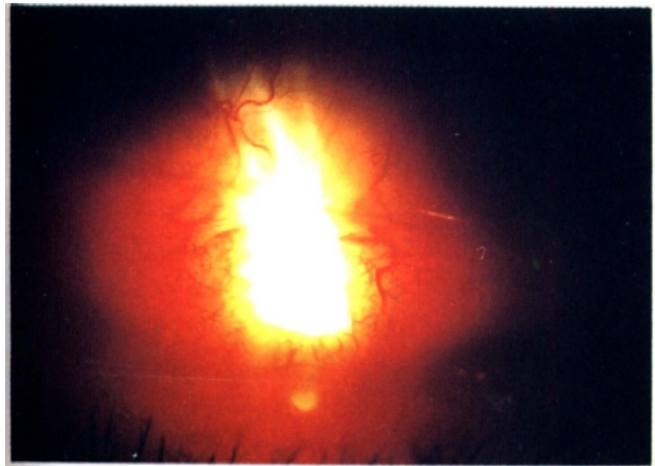

Fig. 4a. Positive fibre optic sign. The tarsal plate is illuminated with a narrow slit beam; a single Meibomian orifice lights up.

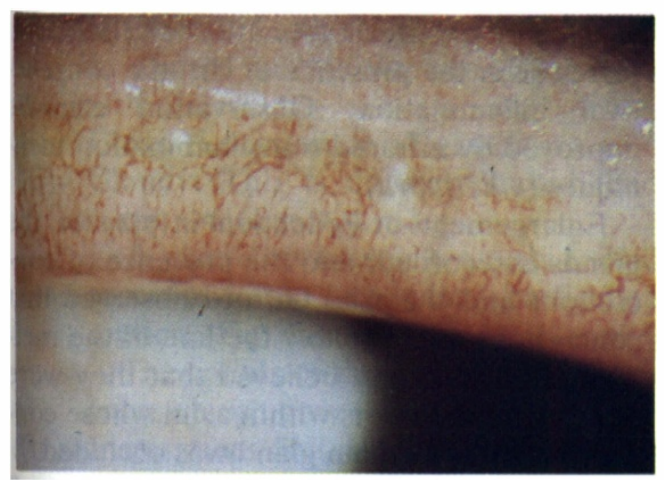

Fig. 4b. Obliterated orifices invaded by new vessels (arrowed).

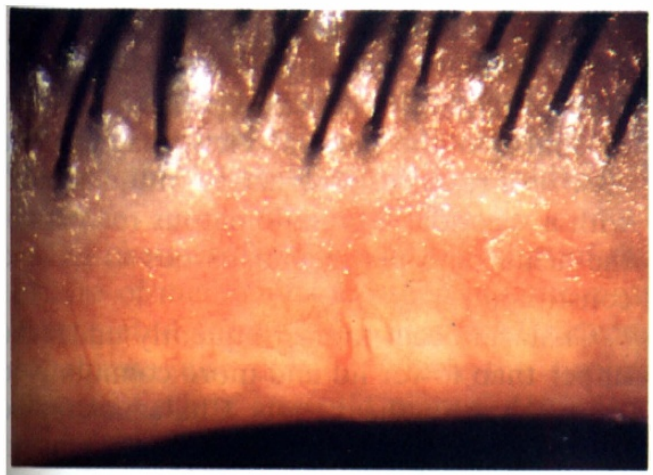

Fig. 4c. Atrophic obliteration of the Meibomian orifices. The orifice structure is no longer seen. The lid margin is relatively avascular and the Meibomian acini are seen through an epithelium which is now translucent.

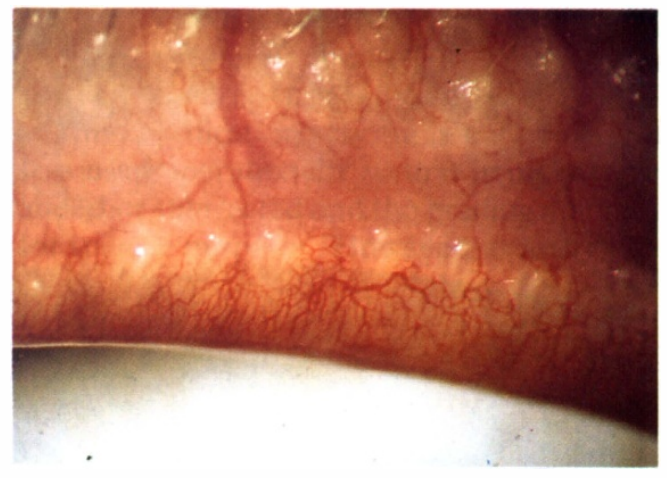

Fig. 4d. MGD: Meibomian duct exposure. Note the large venous tributaries directed anteriorly. One large tributary is draining the pretarsal space. (Arrowed).

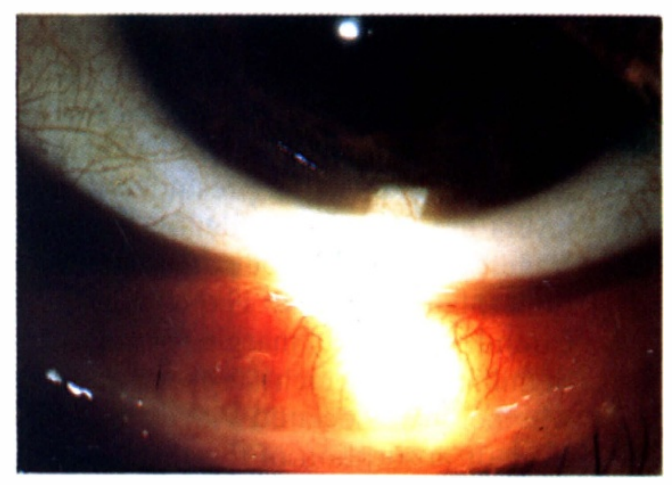

Fig. 4e. Two Cigar-shaped dilations of the Meibomian ducts.

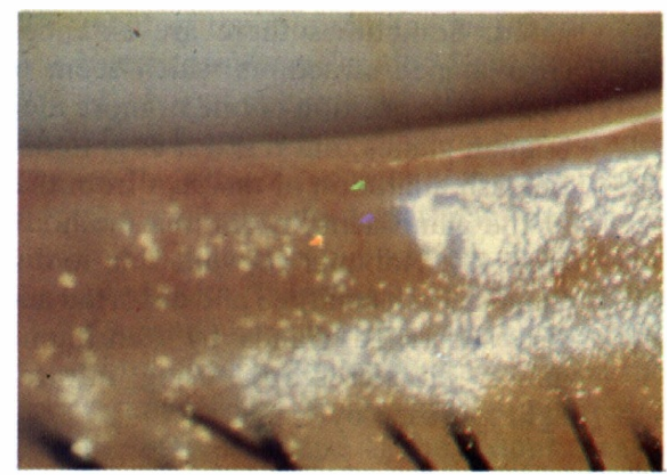

Fig. 4f. A dome of clear oil, expressed at the mouth of a normal Meibomian gland (arrowed). 


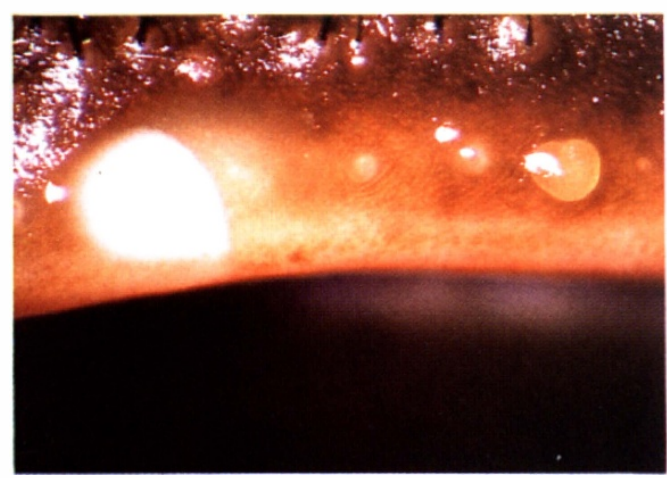

Fig.4g. A dome of very cloudy liquid secretion expressed at the mouth of diseased Meibomian gland (arrow head). A pouting and a capped Meibomian orifice is also seen.

gin, is seen to turn on its side anteroposteriorly, so that it becomes visible at the surface of the lid margin. The outer cuff becomes lost from view, while the inner cuff (the epithelial lining) and the translucent zone (the presumed dermal layer) are seen in profile. In the early stages, the duct may be patent and functional; later it is not. The changes may extend over the lid margin for a number of millimetres, which raises the question whether it is associated with duct elongation, or absorption of the distal part of the tarsal plate. (Fig. 4d).

(ii) Cystoid dilatation: Cystoid expansion may be seen anywhere along the course of the duct as a dark round or ovoid region along the course of a meibomian gland. Sometimes there are extended cigar-shaped structures which seem to occupy the position of one or more meibomian glands, but it is not easy to distinguish dilatation of the duct from that of the gland acini by routine methods. (Fig. $4 \mathrm{e}$ ). Robin et al. were able to distinguish both enlarged and distorted and also shortened glands by transillumination biomicroscopy, using infrared light $^{33}$ as used by Tapie. ${ }^{32}$

\section{Acini}

Visibility: As mentioned above, congenitally absent or deficient glands will be reflected in deficient orifices. Though their presence may readily be judged in young uninflamed lids,

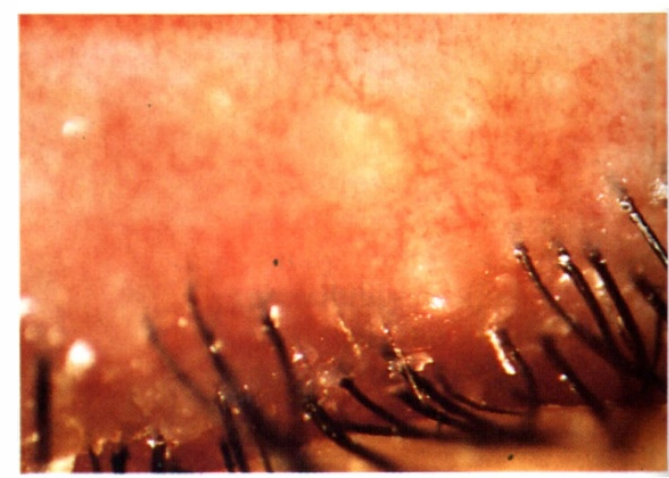

Fig. 4h. A small collection of turbid secretion containing particulate matter, expressed from a diseased Meibomian gland. (Arrowed).

their visibility decreases with age when viewed by diffuse illumination of the tarsal plate, or in the presence of chronic conjunctival inflammation. Observation can be improved by infrared transillumination techniques (vide supra).

Enlargement or reduction in size of the glands is recorded, and the presence of concretions and chalazia. Gifford observed that concretions might follow the line of the meibomian glands, and believed that they were deposits of lime salts within acini whose connection with the main gland was occluded.$^{34}$

The clinical features of chalazia are well known. ${ }^{35}$ Typically a chalazion starts as a hard circumscribed painless elevation on the tarsal plate, visible and palpable through the skin which evolves slowly with time. The lesion is in line with a tarsal gland, which it replaces, and the corresponding ductular orifice is occluded, no oil being expressible. This lends credence to the general view that chalazia arise as a result of obstruction of the gland, ${ }^{36}$ with a secondary, granulomatous reaction of the acinar and peri-acinar tissues to its lipid constituents.

Chalazia occur more frequently under the upper than lower lid and more commonly in adults than in the young. Chalazia may be single or multiple, and they may be confluent. The lid may be sufficiently thickened to prevent eversion. More than one lid may be affected. Multiple chalazia are said to be more frequent in young people, especially seborrhoeic subjects with a history of chronic ble. 
pharoconjunctivitis, ${ }^{37}$ but also in old people or those with rosacea.

\section{Secretions expressed}

The secretory functions of the meibomian glands are assessed indirectly, by compressing the tarsal plate locally in relation to individual groups of orifices. This may be done with finger pressure or with a glass rod, to produce in normal lids, a dome of clear oil over the orifices. Lid oil can be seen at a variable number of normal orifices without expression, (about $64 \%$ ), while about $7 \%$ of orifices open under the tear film in normal lids. ${ }^{38.39}$ Absent secretion, or blockade is encountered with many of the features described in this paper, although their precise relationship has not been quantified.

The quality of expressed secretion which can be elicited in this way in MGD is as follows:

(i) Clear: (i.e. normal). (Fig. 4f).

(ii) Cloudy: This is diffusely turbid fluid secretion. (Fig. 4g).

(iii) Granular: This is usually a turbid, fluid secretion, but contains particulate matter. (Fig. 4h).

The colour of these secretions varies from whitish-grey to yellow.

(iv) Inspissated: This is a semi-solid plug, or of toothpaste-like consistency and may be extruded as a plug, or curled thread. Expression is usually delayed or requires extra pressure. The material contains keratinised epithelial cells. ${ }^{29}$

Another feature which is noted, is so-called meibomian foam, a frothy accumulation on the lid margin or surface of the globe which has been attributed to the presence of soaps in the tear film ${ }^{+1)}$ although supportive evidence is lacking.

The changes described here as part of the picture of meibomitis are seen in their most exaggerated form in the cicatricial mucous membrane disorders in which the further changes include gross lid margin deformity, entropion and trichiasis. It does raise the question whether these and other changes encountered in and described as meibomitis, are due primarily to the periacinar subepithelial cicatricial disease rather than to primary diseases of the gland itself. However it is not excluded that either or both primary meibomian gland disease or subepithelial scarring could be responsible.

The classification scheme is not complete. It is used operationally so that items may be added or subtracted and the grading adjusted for specific purposes. However, as many features as possible have been included as are thought to have relevance to the assessment of meibomian gland dysfunction. The schema was designed to permit a detailed assessment of meibomian and lid morphology for the purposes of natural history and therapeutic studies.

The purpose of classifying the features of MGD is the opportunity which it provides to quantify them. The grading scheme is also illustrated in Table III. Certain generalisations may be made:

\section{Extent of Change}

(1) Whatever the grade, the extent of lid affected is recorded on a $0-4$ basis to represent length (of lid margin) or area (of tarsal plate) involved, in quarters (i.e. $0,1,2,3,4,=$ Nil, $0.25,0.5,0.75,1)$.

\section{Degree of Change}

(1) Some features are graded on a dichotomous scale (0/1: present or absent) e.g. concretions, cysts, trichiasis etc.

(2) Other features are graded 0-3. This represents either mild, moderate or marked change, or the features are individually characterised e.g. retroplacement of the mucocutaneous junction, or duct exposure are graded according to the number of millimetres of involvement.

(3) Many features may show multiple grades on the same lid margin or tarsal surface. For example, the tarsal plate may show fine papillae in one region and cobblestones in another. In the scheme described here for degree of change, the most advanced feature is scored. But the extent recorded refers to all categories of the stated feature. (The extent clearly could be scored for each grade of the feature but unless there is a specific purpose, this is too cumbersome for routine use).

(4) For lid thickness, which may show a quantitative increase or decrease the grading is 
$1-5$, with grade 3 representing 'normal' thickness, grades 1 and 2 representing decreased and grades 4 and 5 representing increased thickness. In this and certain other cases, actual measurement can replace grading. (e.g. of lid thickness, retroplacement of orifices, exposure of the main ductules).

Some examples of grading are given below:

\section{Lid Margin}

Rounding is graded $0 / 1$; present or absent and the length of lid affected as $0-4$.

Vascularity is graded as reduced $(0 / 1)$, increased (0/1) and telangiectasia (0/1) and extent affected for each feature recorded as 0-4. Cutaneous hyper-keratinisation, squamous blepharitis, trichiasis, malapposition in primary position or upgaze, are graded as present or absent $(0 / 1)$ and the extent of lid affected graded $0-4$.

\section{Mucocutaneous Junction}

Anteroplaced: Anterior movement of the mucocutaneous junction is scored $0-3$, dividing the normal width of the skin between the normal MCJ and anterior lash line into thirds and grading accordingly. The highest grade noted is scored and the extent of length of lid affected by any abnormality of this kind is scored $0-4$.

Retroplacement of the MCJ is measured with reference to its normal estimated location. It may move up to $1 \mathrm{~mm}$ posterior (grade 1 ); it may lie $>1 \mathrm{~mm}$ but less than $2 \mathrm{~mm}$ posterior (grade 2 ), or it may lie $>2 \mathrm{~mm}$ (grade 3 ).

It will be noted, that if the mucosa of the lid margin is absorbed, then the MCJ does not necessarily move back as a result. Mucosal absorption or ridging are recorded as present or absent $(0 / 1)$ and the length of lid affected recorded as $0-4$.

\section{Orifices}

Reduction: The pattern of meibomian orifices is so regular that absence of orifices can readily be estimated by gaps in the rows or by examination of acini when these are visible as in the young. Abnormality is graded as $0 / 1$; the length affected $0-4$. (The sum of lengths over which the feature is absent is totalled for this purpose, and this is a general principle where length or area of abnormality are scored.

\section{Discussion}

Many aspects of MGD and its treatment were known to ophthalmologists one hundred and fifty years ago. Attempts to classify it then as now, combined morphological features with clinical associations in such a way as to generate artificial subgroups which were not mutually exclusive.

MacKenzie was the first to mention chronic meibomitis as part of the condition of 'ophthalmia tarsi', in which the oil glands were distended, and thickened (puriform) secretions were present in increased amount. ${ }^{+1}$ Scarpa described a similar 'puriform palpebral flux'. ${ }^{42}$ Elschnig provided a classical description of meibomian gland disease and emphasised the value of lid massage, at first daily and then at longer intervals, in treatment. ${ }^{43 .+4}$ Gifford described six types of disease as follows; ${ }^{3+}$

\section{Type 1: Simple Hypersecretion}

The expressed secretion of the glands was abnormal, being a waxy material usually in the form of semi-solid coils, but which could be of a softer consistency. The condition was associated with few or no symptoms and with the presence of a frothy scum (equivalent to the current term 'meibomian foam'), at the inner canthus.

\section{Type 2: Simple Chronic Meibomitis (Simple Inflammation)}

Gifford conceived this type to be similar to type 1 and perhaps derived from it. Lid pressure may express a fluid of granular composition ('grumous') or a whitish or yellowish, cloudy secretion, less solid than in type 1 . Ducts were found to be obstructed in some glands and acini less visible because of greater opacity of the conjunctiva. Cases affected with type 2 disease showed thickening of the lids with inflammation of the ciliary margin.

\section{Type 3: Chronic Meibomitis with Hypertrophy}

This was thought to be a more advanced form of stage 2, with congested and distended glands. Gifford described 'a strip of hypertrophied conjunctiva, roughened and raised 
above the tarsal conjunctiva and often occluding the mouths of some glands'.

Three further types were described on the basis of an association of meibomian disease with other affections such as chalazia, conjunctivitis, and concretions.

\section{Type 4: Chronic meibomitis with chalazia}

In this association, the lids were thickened and a honey-like secretion could be expressed from all glands. Particular attention was given to the occurrence of multiple chalazia, occurring as early as $7 / 12$ of age (e.g. around 30 chalazia) and generally presenting at an earlier age (usually under 40 years) than the other forms referred to above.

This association between meibomian gland disease and chalazia was earlier referred to by Addaria in 1888 (leading to difficulty in complete lid opening in extreme cases $)^{45}$ and by Dianoux $^{37}$ and Natanson. ${ }^{46}$ It is a generally accepted association with meibomian dysfunction. ${ }^{35}$

\section{Type 5: Chronic meibomitis secondary to chronic conjunctivitis}

In this situation, typified by the events in atrophic trachoma (stage 4), there is a dense connective tissue formation overlaying and between the acini, which often occludes ducts leading to the formation of retention cysts.

\section{Type 6: Chronic meibomitis is associated with tarsal concretions}

In case reports concretions are identified as being irregularly disposed along the gland acini.

More recently McCulley et al. have provided a classification of anterior and posterior blepharitis which combines a morphological description with an analysis of microbiological findings. ${ }^{47}$ The morphological descriptions, with a detailed account of meibomian gland changes, evolved from earlier studies of meibomian keratoconjunctivits by McCulley and Sciallis. ${ }^{48}$

Categories described by McCulley et al. are as follows: ${ }^{47}$ (Table IV).

Seborrhoeic Blepharitis, is a marginal anterior blepharitis characterised by lid crusting, and scaling which is more oily than in staphylococcal blepharitis and with less anterior (ciliary) lid inflammation (in the absence of a staphylococcal superinfection).

There may be an associated meibomian seborrhoea or secondary meibomitis (vide infra) with dilated ductules filled with an excess of meibomian secretions, and in $95 \%$ of cases there is an associated seborrhoeic dermatitis. The latter in their series was usually mild, and variably involved scalp, retroauricular skin, the nasolabial folds, brow and sternum.

'Staphylococcal blepharitis' was essentially a clinical diagnosis in keeping with classical descriptions of this entity. ${ }^{49}$ There is relatively more anterior ciliary inflammation than in seborrhoeic blepharitis and less greasy crusts and scales. There is only occasionally a follicular or papillary conjunctivitis or punctate keratitis $(15 \%)$. Keratoconjunctivitis sicca occurs in $50 \%$ of cases and it is preponderant in women $(80 \%))^{47}$

In their series, culture was positive for staphylococcus aureus in $50 \%$, and for staphlyococcus epidermidis in the remaining $50 \%$. The relative prevalence of staphylococcus aureus, either alone or in combination with seborrhoeic blepharitis was thought to have decreased in recent years. Only the staphylococcal group and mixed seborrhoeic/staphylococcal group showed an excess of positive cultures for staphylococcus aureus. ${ }^{47}$

\section{Meibomian Seborrhoea}

Meibomian hypersecretion was recognised by Gifford $^{3+}$ although the term meibomian seborrhoea was coined by Cowper. ${ }^{50}$ It is not clear that all authors used the term in an identical way. McCulley et al. use the term to describe a condition in which an excess of secretion, contained in dilated ductules may be expressed in normal liquid form. ${ }^{47}$

There are limited, or no signs of inflammatory lid disease. It is not yet established whether this is a true hypersecretion, or the result of duct stasis and the expression of accumulated secretions. The dilemma persists, even though some authors remark on the rapid reaccumulation of excessive secretions after therapeutic expression.

Primary meibomitis is described as an inflammation around the meibomian orifices diffusely affecting all the glands to a similar 
Table IV Forms of blepharitis

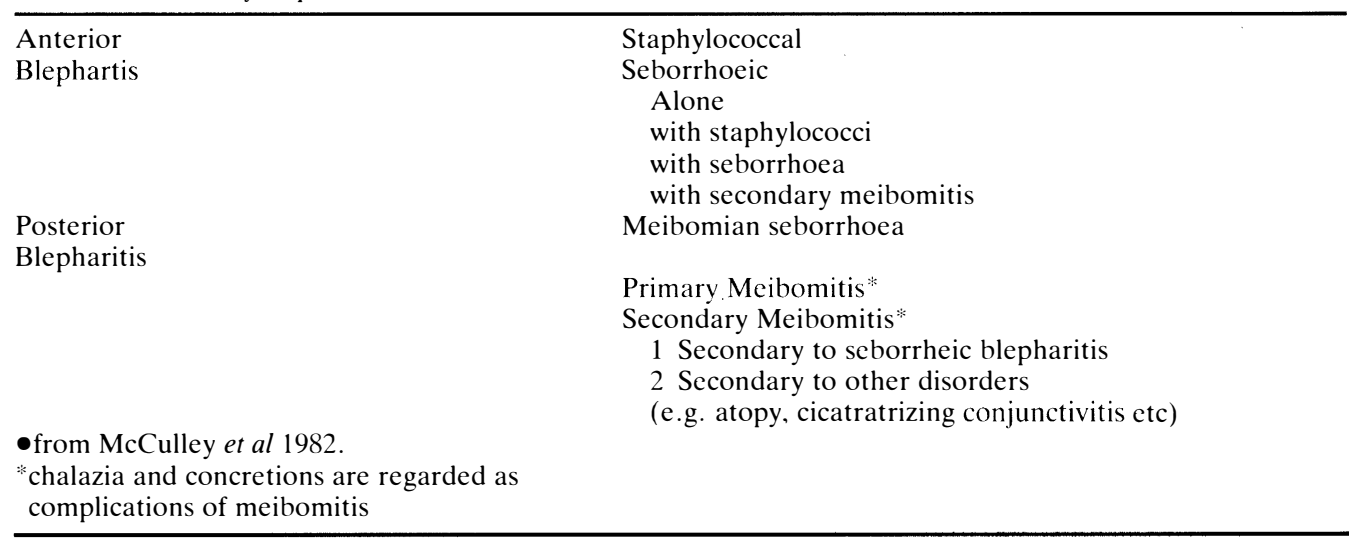

degree. Solidification of the lipid secretions is prominent with resulting plugging of gland orifices and build-up of secretions. Primary meibomitis is associated with bulbar injection and tarsal papillary hypertrophy in addition to superficial punctate keratitis and a reduced break-up time. ${ }^{48}$

The condition was found to be associated with a seborrhoeic dermatitis in $36 \%$ and acne rosacea in $63 \%$ of cases. Patients are regarded as having a generalised problem of their sebaceous glands which also affects the meibomian glands.

No specific pathogen is isolatable.

Meibomitis secondary to seborrhoeic blepharitis is a patchy affection of the meibomian glands occurring in clusters along the lid margin. The tissue surrounding the glands is inflamed, and secretions within the ductules are solidified and difficult to express. Secondary meibomitis is associated in $100 \%$ of cases with seborrhoeic dermatitis. The condition is associated with symptoms of burning.

In both primary and secondary meibomitis the frequency of staphylococcus aureus culture is low and not in excess of that encountered in control lids. When organisms are cultured from expressed meibomian secretions, they are the same as those cultured from the lid. A further secondary category was described including atopic, psoriatic and fungal causes of meibomian gland dysfunction (Table IV).

In an earlier study of meibomian keratoconjunctivitis, those patients $(15 \%)$ whose meibomitis was associated with seborrhoeic dermatitis and atopy had the most severe signs, with secretions more difficult or impossible to express and with plugs extending deeper into the glands.

In this paper we have concentrated on the components which go to make up posterior blepharitis in the view that the detailed description of these changes is both scattered in the literature and also is incomplete. It is our particular interest to provide a tool to follow the natural history of the changes described and their grouping within the major classes summarised by McCulley et al. ${ }^{48}$ and to study not only their relation to anterior blepharitis and dermatological status but also the overlap of occurrence of specific features within each category and their evolution with time. A proper understanding of such events will also require a description of the changes in lid structures which occur with age and this is being undertaken.

\section{References}

li: Jester JV, Nicholaides N, Smith RE: Meibomian gland dysfunction. I. Keratin protein expression in normal human and rabbit meibomian glands. Invest Ophthalmol Vis Sci 1989a, 30: 927-35.

th Meibomius H: De Vasis palpebrarum Novis Epistola p. 23. Müller, Helmstädt.

'Neumann F and Elger W: The effect of a new antiandrogenic steroid, 6-Chloro-17-Hydroxy-1 $\alpha, 2 \alpha$ Methylene Pregna-4, 6-Diene-3, 20 Dione Acetate (Cyproterone Acetate) on the sebaceous glands of mice. J Invest Dermatol 1966, 46: 561-72.

${ }^{3}$ Strauss JS and Pochi PE: Assay of anti-androgens in man by the sebaceous gland response. $\mathrm{Br} J \mathrm{Der}$ matol 1970, 82 (Suppl 60): 33-42.

${ }^{+}$Schuster S and Thody AJ: The control and measurement of sebum secretion. J Invest Dermatol 1974, 62: $172-90$. 
${ }^{5}$ Zaun H: Zur hormonelle Becinflussung der Talgsekretion. Fette Seife Anstrichtsmittel 1979, 81: 130-3.

${ }^{6}$ Zlotogorski A, Glaser B, Berovici B, Dikstein S: Sebum measurements for rapid identification of hyperandrogenism. (in press).

${ }^{7}$ Hartschuh W, Weihe E, Reinecke M: Peptidergic (neurotensin, VIP, substance P) nerve fibres in the skin. Immunohistochemical evidence of an involvement of neuropeptides in nociception, pruritis and inflammation. Br J Dermatol 1983, 109 (Suppl 25): 14-7.

${ }^{8}$ Buschke A and Fränkel A: Ueber die Funktion der Talgdrüsen und deren Beziehung zum Fettstoffweschel. Berlin-Klin Wshcr 1905, 24: 318-22.

"Jester JV, Rife L. Nii D, Luttrull JK, Wilson L, Smith RE: In vivo biomicroscopy and photography of meibomian glands in a rabbit model of meibomian gland dysfunction. Invest Ophthalmol Vis Sci 1982, 22: 660-7.

"Jester JV, Nicholaides N, Kiss-Polvolgyi I, Smith RE: Meibomian Gland Dysfunction. II: The role of keratinisation in a rabbit model of MGD. Invest Ophthalmol Vis Sci 1989b, 30: 936-45.

${ }^{11}$ Killey FP, Minckler DS, Smith RE, Spencer JA: The effect of long term epinephrine in the rabbit eye. (ARVO abstracts). Invest Ophthalmol Vis Sci 1980, 19 (Suppl): 253.

${ }^{12}$ Tiffany JM and Dart JKG: Normal and abnormal functions of meibomian gland secretions. Roy Soc Med Int Congr Symp Ser 1981, 40: 1061-4.

${ }^{13 a}$ Wolff E: The mucocutaneous function of the lid margin and the distribution of the tear fluid. Trans Ophthalmol Soc UK 1946, 66: 291-308.

${ }^{13 \mathrm{~b}}$ Linton RG, Curnow DH, Riley WJ: The meibomian glands: An investigation into the secretion and some aspects of the physiology. Br J Ophthalmol 1961, 45: 718-23.

${ }^{14}$ McDonald JE: Surface phenomena of tear films. Trans Am Ophthal Soc 1968, 66: 905-9.

${ }^{15}$ Josephson JE: Appearance of the preocular tear film lipid layer. Am J Optom Physiol 1983, 60: 883-7.

${ }^{16}$ Tiffany JM: The lipid secretion of the meibomian glands. Adv Lipid Res 1987, 22: 1-62.

${ }^{17}$ Tiffany JM: The role of meibomian secretion in the tears. Trans Ophthalmol Soc UK 1985, 104: 396-401.

${ }^{18}$ Nicolaides N: Recent finding on the chemical composition of the lipids of steer and human meibomian glands. In 'The Preocular Tear Film' ed .F. Holly, pp. 570-596 Dry Eye Institute, Lubbock, Texas 1986.

${ }^{19}$ Virchow H: Microscopic anatomy of the outer coats of the eye and the lids (German). In 'Graefe-Saemisch Handbuch der gesamten Augenheilkunde' ed T. Saemisch, 1910, Vol 1, Part 1, Ch 2.

${ }^{27}$ Duke Elder WS and Wybar KC: The anatomy of the visual system. Vol II of the system of Ophthalmology. H Kimpton, London 1961.

${ }^{21}$ Wolffe E: Anatomy of the Eye and Orbit. Seventh edition. Ed R Warwick 1976. HK Lewis, London.

${ }^{22}$ Murube del Castillo J: Dacriologia Basica p 432. Soc Esp Oftal, Las Palmas 1981

${ }^{23}$ Bron AJ and Mengher LS: Congenital deficiency of meibomian glands. $\mathrm{Br} J$ Ophthalmol 1987, 71: 312-4.

${ }^{24}$ Holly FJ and Lemp MA: Tear physiology and dry eyes. Surv Ophthalmol 1977, 22: 69-87.
${ }^{25}$ Baum JL and Bull MJ: Ocular manifestations of the ectrodactyly, ectodermal dysplasia, cleft lip-palate sýndrome. Am J Ophthalmol 1974, 78: 211-16.

${ }^{26}$ Mondino BJ, Bath PE, Foos RY, Apt L, Rajacich GM: Absent meibomian glands in the ectrodactyly ectodermal dysplasia, cleft lip-palate syndrome. Am J Ophthalmol 1984, 97: 496-500.

${ }^{27}$ Bron AJ, Tiffany JMT, Kaura R, Mengher LS: Disorders of tear lipids and mucous glycoproteins. In: DL Easty, GS Molin eds. External eye disease. London: Butterworths 1984. 63-105 Theodore.

${ }^{24}$ Korb DR and Henriquez AS: Meibomian gland dysfunction and contact lens intolerance. J Am Optom Assoc 1980, 51: 243-51.

${ }^{24}$ Henriquez AS and Korb DR: Meibomian glands and contact lens wear. $B r J$ Ophthalmol 1981, 65: 108-11.

31) Gutgesell VJ, Stern GA, Hood CI: Histopathology of meibomian gland dysfunction. Am J Ophthalmol 1982, 94: 383-7.

${ }^{31}$ Kieth CG: Seborrhoeic blepharo-kerato-conjunctivitis. Trans Ophthalmol Soc UK 1967, 87: 85-103.

${ }^{32}$ Tapie R: Etude biomicroscopique des glandes de Meibomius. Ann Oculist 1977, 210: 637-48.

${ }^{3.3}$ Robin JB, Jester JV, Nobe J, Nicolaides N, Smith: In vivo transillumination biomicroscopy and photography of meibomian gland dysfunction. Ophthalmology 1985, 92: 1423-6.

${ }^{34}$ Gifford SR: Meibomian glands in chronic blepharoconjunctivitis. Am J Ophthalmol 1921, 4: 489-94.

${ }^{35}$ Duke-Elder S: System of Ophthalmol. XIII. The Ocular Adnexa. Part I Diseases of the eyelids. p. 241-250, Sir S Duke-Elder and PA MacFaul. Pub. H Kimpton, London 1974.

${ }^{36}$ Deyl: Ueber die Ätiologie der Chalazion, Prague 1893.

${ }^{37}$ Dianoux: La conjonctivite a chalazion. Arch d'Ophthal 1891, 11: 302 .

${ }^{3 *}$ Norn MS: Natural fats in external eye. Vital stained by Sudan III. Acta Ophthalmol 1980 58: 331-6.

${ }^{34}$ Norn MS: Meibomian orifices and Marx's line. Studied by triple staining. Acta Ophthamol 1985, 63: 689-700.

${ }^{40}$ Norn MS: Foam at outer palpebral canthus. Acta Ophthalmol 1963, 41: 531-7.

${ }^{41}$ Mackenzie: A practical treatise on diseases of the eye. 2nd edition. London P. 149. 1835.

42 Scarpa: Arch di Otti 1897, 82.

${ }^{43}$ Elschnig A: Die massage in der Augenheilkunde. Wiener medizinischen presse 1901 no. 18 und 19.

${ }^{44}$ Elschnig A: Beitrag zur Aetiologie und therapie der chronischen conjunctivitis. Deutsch med Wschr 1908, 34: 1133 .

${ }^{45}$ Addario: Sci di un caso di calazio multiplo e di tarsite cronica diffusa di tutte e quattro le palpebre. Ann di Ott 1988, 17: 259.

${ }^{\text {th }}$ Natanson A: Chronische multiple eitrige Entzündung der Meibomschen Drüsen. Klin Mbl. $f$. Augenhlk 1907, 45: 529.

${ }^{47}$ McCulley JP, Dougherty JM, Deneau DG: Classification of chronic blepharitis. Ophthalmology 1982, 89: 1173-80.

${ }^{+8}$ McCulley JP and Sciallis CF: Meibomian keratoconjunctivitis. Am J Ophthmol 1977, 84: 788-93.

${ }^{t y}$ Thygeson P: Etiology and treatment of blepharitis. A study in military personnel. Arch Ophthalmol 1946, 36: 445-77.

${ }^{50}$ Cowper HW: Meibomian seborrhoea. Am JOphthalmol 1922, 5: 25-30. 